Projeto do Codigo Criminal brasiletro, par Alcantara Machado, Professor à la Faculté de Droit de São Paulo - São Paulo - Emprêsa Gráfica da Revista dos Tribunais - 1938, 1 vol. in $8 .^{\circ}$ de 304 pages.

Nous avons, il y a quelques mois, fait paraitre dans cette revue un compte rendu détaillé du remarquable Avant-projet du Code pénal brésilien, rédigé par M. le professeur alcantara Machado.

L'auteur vient de publier le texte définitif du Projet de Code penal que le Ministre de la Justice, professeur Dr. Francisco Campos l'avait chargé de préparer. L'œuvre comprend deux grandes parties. La première intitulée Parte Geral (partie générale) est consacrée aux infractions et à la répression en général. Le titre VII intitulé $D a$ ação criminal (de l'action publique) contient les règles relatives à l'exercise de l'action pour l'application des peines et à l'extinction des poursuites repressives.

Les differences entre le texte de l'Avant projet de la partie générale et celui du livre I du projet définitif sont relativement peu importantes.

M. Machado a simplement modifié legèrement le texte de certains articles de manière à prevenir des controverses possibles.

Signalons simplement que l'article 12 de l'Avant-projet porte qu'en cas de désistement volontaire la tentative n'est pas punissable. L'article II du Projet qui correspond à la disposition prémentionnée de l'Avant-projet exige le désistement-spontané pour la nonpunissabilité de la tentative simple.

Ainsi l'auteur supprime la difficulté consistant à déterminer dans un cas concret si le désistement a été imposé à l'agent par lat crainte d'un mal imminent ou s'il a été volontaire et provoqué soit par la crainte de la peine soit par un réveil tardif de la conscience.

Le livre II intitulé Parte especial traite des infractions et do leur répression en particulier.

Il nous est impossible d'exposer dans ce compte rendu forcément bref, toutes les différences qui existent entre notre droit pénal et le projet de M. Machado. Nous signalerons simplement à titre indicatif quelques points particulièrement intéressants:

La provocation, l'aide ou l'assistance au suicide consommé ou tenté sont érigées en infraction. La peine comminée est fortement augmentée si l'agent a obéi à des mobiles égoïstes ou honteux, quand la victime est mineure de dix-huit ans ou, pour une cause quelcon- 
que, ne jouit pas de la plénitude de ses facultés mentales (não estiver em seu perfeito juizo).

Notre droit positif n'attache, tout au moins en règle générale, aucune importance au mobile déterminant qui a poussé l'agent au délit. C'est une erreur regrettable sur laquelle tous les criminalistes modernes mettent l'accent.

Il n'est en effet plus sérieusement contesté aujord'hui que la valeur symptomatologique du délit beaucoup plus du mobile auquel l'agent a obéi que de la place que le droit violé occupe dans l'échelle de la valeur des biens.

Nos lecteurs n'ignorent certes aucune des difficultés que sorieve la répression de l'avortement. Nous attirons leur attention sur les points suivants:

1. ${ }^{\circ}$ Le project ne punit pas les manœuvres abortives quand elles n'ont pas provoqué l'interruption prémature de la grossesse ni quand celle-ci est la conséquence d'un viol (art. 314, $§ 2$, I et II).

2.0) L'avortement provoqué par un médecin autorisé, quand il n'y a pas d'autre moyen pour sauver la vie de la femme gravide.

3.') De même échappe à la répression l'interruption de grossesse provoquée par un médecin autorisé, du consentement de la femme enceinte ou, si celle-ci est incapable de donner un consentement valable, du consentement de son représentant légal, pourvu bien entendu, que la grossesse soit la conséquence d'un viol.

L'infanticide commis pour cacher son propre déshonneur ou celui d'une ascendante, descendante, belle-fille ou épouse, est puni moins sévèrement que l'homicide (art. 312). En cas d'entretien de concubine, la concubine est punie au même titre que l'epoux infidèle.

L'adultère, l'entretien de concubine ne peuvent donner lieu à poursuite que si l'époux offensé porte plainte. Ne peut porter plainte l'époux qui a donné son consentement à la violation de la foi conjugale, ni celui qui abandonné le domicile conjugal.

L'inceste est puni, mais seulement s'il est commis de manière à donner lieu à scandale public.

La conjonction charnelle accomplie à l'aide de violences, menaces, fraudes est punie en principe de 3 à 10 ans de réclusion (la plus sévère des peines privatives de liberté prévues par le Projet).

Parmi les circonstances aggravantes spéciales à cette infraction signalons le fait que, par suite du crime, la victime a contracté la syphilis, la blennoragie ou quelqu'autre affection vénérenne.

Des peines sévères, privatives de liberté et patrimoniales, sont comminées contre les proxénètes. 
La répression atteint même le souteneur passif, celui qu'on appelle dans les Congrès pour la répression de la traite des blanches: le parasite de la prostituée.

Les atteintes à l'honneur sont réprimées par des peines énergiques.

L'art. 336 sauvegarde toutefois les droits de la critique littéraire, artistique, scientifique, pourvu que cette critique ne soit pas équivoque et que l'intention d'injurier ou de diffamer y demeure étrangère.

En bref, le projet de Code penal brésilien est remarquable à des points de vue nombreaux et variés.

Il est, parmi tant d'autres, une preuve éclatante des progrès immenses réalisés par le droit pénal et les sciences criminologiques dans les Etats de l'Amérique latine, au cours de ces vingt dernières années (1). Ceux qui prétendent réformer le droit pénal belge, feraient chose sage en lisant le livre de M. Machado.

\section{JULES SIMON}

(Conseilier á la cour d'Appré de Bruxelles, Professeux de droit pénal à L'Universitá de Gaud)

(I) A ceux qui en douteraient nous conseillerons la lecture du Codice della difesa sociale - I lege contro l'antisocialita, préparé par l'avocat F. F. Gramatica. - Gênes 1938, vol. I. (Rapport) in $8^{\circ}$ de $198 \mathrm{p}$.

(Transerito da "Revue de droit pénal et de crirainologie", de Bruxelas, 1938, março). 